PAPERS

\title{
An improved method of model predictive current control for multilevel cascaded $\mathbf{H}$-bridge inverters
}

\author{
Chung Mai-Van ${ }^{1,2}$, Sang Duong-Minh ${ }^{1}$, \\ Duc Tran-Huu ${ }^{1}$, Bao Binh-Pho ${ }^{1,3}$, Phuong Vu ${ }^{1 *}$
}

\begin{abstract}
Finite control set ModelPredictive control (FCS-MPC) with the principle of considering all voltage vectors to find the optimal voltage vector for multilevel inverter in a very small sampling cycle is hardly feasible because there is no modulation part, the implementation of optimizing common-mode voltage and switching number for the multilevel inverter should be performed in the cost function. To solve the above problem, this paper proposes an improved method of model predictive current control selecting 19 adjacent voltage vectors and using weighting coefficients for common-mode voltage elimination and switching optimization. By using a discrete-time model of the system to predict the future value of the current for the voltage vector in the previous sampling cycle and its 18 adjacent voltage vectors, the one that minimizes a cost function will be selected. Thus, in a multilevel inverter with any number of levels, the cost function is performed only 19 times in a sampling cycle. The computation on FPGA allows 19 calculations of the cost function to be performed in parallel, so the executing time is very small. The feasibility of the proposed algorithm is verified by simulation model on MATLAB-simulink software and the experimental 11-level cascaded H-bridge multilevel inverter model.
\end{abstract}

Keywords: predictive current control, cascaded hbridge (CHB), multilevel inverter, the number of calculations, common-mode voltage (CMV)

\section{Introduction}

Multilevel inverters have been widely used in highvoltage and high-power applications thanks to their advantages: Low total harmonic distortion (THD) of output waveforms [1], reducing the voltages applied to power semiconductor components, and voltage changing $(\mathrm{d} v / \mathrm{d} t)$ at lower speed $[2,3]$. Especially, the CHB multilevel inverter structure described in [4-6], has high modularity and many preventive voltage vectors creating the same voltage levels in each phase, so it raises the reliability of inverters in error situation. In addition, CHB does not need extra elements such as diodes [7], capacitors $[8,9]$. Therefore, the CHB multilevel inverter structure is widely used in industry for different applications, such as static synchronous compensators [10,11], converters for high power motors [12,13], and converters for grid-connected application of renewable energy sources $[14,15]$.

Nowadays, FOC is still considered as the standard control method in the industry $[16,17]$. To improve the dynamics of the FOC control method, many new methods of the current control is being studied such as: using neural network, fuzzy control and MPC [18]. In which, MPC method is very attractive because of several advantages such as: easy to approach, being a multi-variable MIMO controller, capable of working with non-linear systems in time domain, having fast dynamic response, flexibility of the cost function in choosing control objects or adding more constraints. Therefore, the MPC method is the potential alternative control method in power electronics and electric drive $[19,20]$.

One of the limits of the MPC method is the requirement of controller's large computational capable. Specially, when the drive system is powered by a multilevel inverter, the number of voltage vectors increases rapidly, depends on the number of levels. Therefore, the amount of calculations in each sampling cycle will also increase. The total calculating quantity is $(2 n+1)^{3}$, where $n$ is the number of H-bridges in each phase of the CHB inverter $[19,21]$.

However, the too large computational volume may make it impossible to implement due to the limited resource of the control device. Moreover, it will take more time to complete calculating, affect the controller's quality. There have been many studies to reduce the computational volume of the MPC method. For example, [22] proposes a method of using 7 adjacent voltage vectors and $12 n^{2}+6 n+1$ nonredundant voltage vectors. It just chooses one from the 7 voltage vectors group, which includes the voltage vector in the previous sampling cycle and 6 voltage vectors around it. This ensures that the computational amount of the cost function is constant, giving a fixed number of calculations regardless of any levels of the multilevel inverter. However, selecting only 7 adjacent voltage vectors in [22] affects the quality of the

\footnotetext{
${ }^{1}$ School of Electrical Engineering, Hanoi University of Science and Technology, Hanoi, Vietnam, ${ }^{2}$ Hung Vuong University, Phu Tho, Vietnam, ${ }^{3}$ National University of Civil Engineering, Hanoi, Vietnam, * corresponding author: phuong.vuhoang@hust.edu.vn
} 

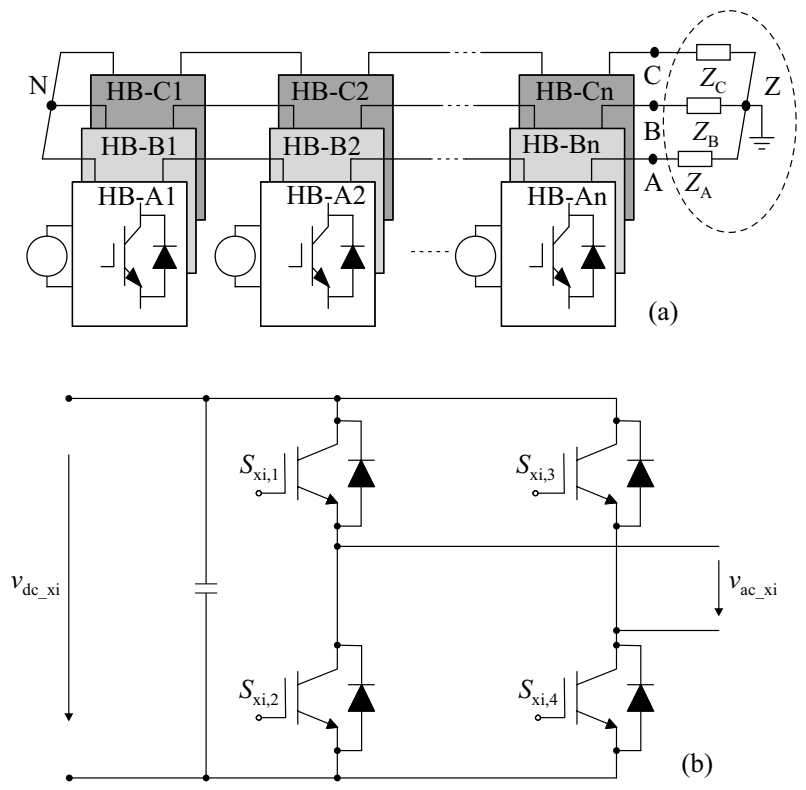

Fig. 1. (a) - topology of a CHB multilevel inverter, (b) - structure of a H-bridge

controller, especially in transition. Besides, that method is not capable of eliminating common-mode voltage or optimizing the switching number. Thanks to the development of microcontrollers and FPGA in recent years, the problem of large computational number of MPC can be solved. Therefore, in this study, the author will propose an improved method of MPC for the cascaded H-bridge multilevel inverter with below objectives: Reducing the computational amount of the cost function by using 19 adjacent voltage vectors, eliminating common-mode voltage and optimizing the switching number.

\section{Cascaded H-bridge multilevel inveter}

\subsection{CHB multilevel inverter}

The topology of a three-phase CHB multilevel inverter is shown in Fig. 1(a). Each phase of CHB multilevel inverter is made up of many power cells connected in series. A power cell is a single-phase $\mathrm{H}$-bridge inverter.

Assume that each phase of CHB multilevel inverter is made up of $n$ cells and each cell is powered by an independent dc voltage source $V_{\mathrm{dc}}$. Fig. 1 (b) shows the structure of H-bridge $i$, where $x$ represents phase $a, b$ or $c$ and $i$ is from 1 to $n$. The semiconductor switches in each cell can be controlled to generate three voltage levels $V_{\mathrm{dc}}, 0,-V_{\mathrm{dc}}$ corresponding to cell states $\{1,0, \ldots,-1\}$. The voltage level of each phase is the sum of cell levels of all its cells

$$
S_{x}=\sum_{i=0}^{n} S_{x i} .
$$

The total number of possible voltage levels for each phase is

$$
m=2 n+1
$$

The inverter's voltages of each phase are calculated by

$$
\left\{\begin{array}{l}
v_{\mathrm{AN}}=V_{\mathrm{dc}} \sum_{i=0}^{n} S_{\mathrm{ai}}, v_{\mathrm{BN}}=V_{\mathrm{dc}} \sum_{i=0}^{n} S_{b i} \\
v_{\mathrm{CN}}=V_{\mathrm{dc}} \sum_{i=0}^{n} S_{c i}, v_{\mathrm{ZN}}=\frac{1}{3}\left(v_{\mathrm{AN}}+v_{\mathrm{BN}}+v_{\mathrm{CN}}\right) \\
v_{\mathrm{A}}=v_{\mathrm{AN}}-v_{\mathrm{ZN}}, v_{\mathrm{B}}=v_{\mathrm{BN}}-v_{\mathrm{ZN}} \\
v_{\mathrm{C}}=v_{\mathrm{CN}}-v_{\mathrm{ZN}}
\end{array}\right.
$$

\subsection{Space voltage vectors of 11-level CHB inverter}

A voltage vector is created by a combination of switching states. In the CHB inverter having $\mathrm{n}$ cells per phase, the total number of switching states combinations is

$$
K_{m}=(2 n+1)^{3} \text {. }
$$

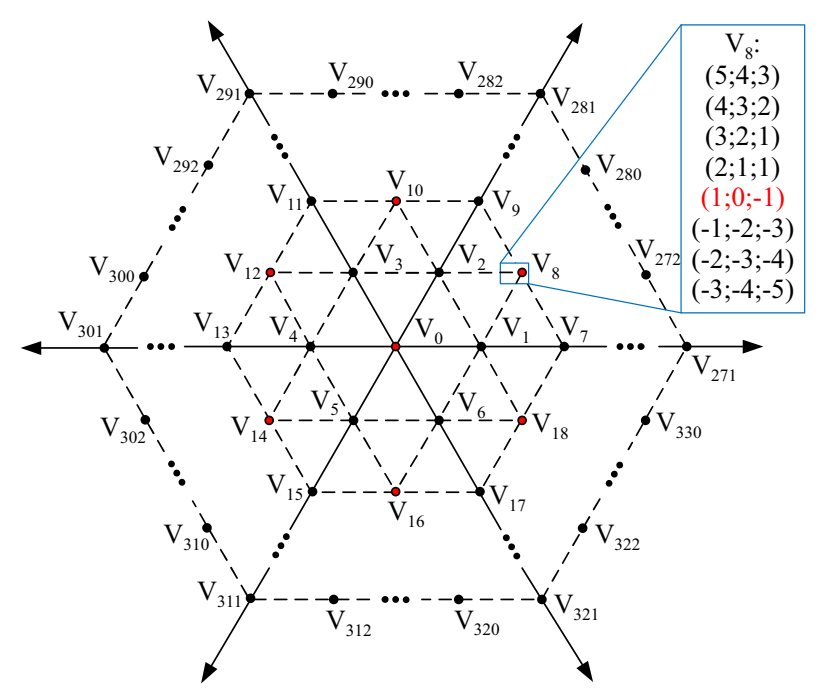

Fig. 2. Space voltage vectors of a three-phase 11-level CHB inverter

In multilevel CHB inverters, there are many sets of switching states combinations that can generate the same 


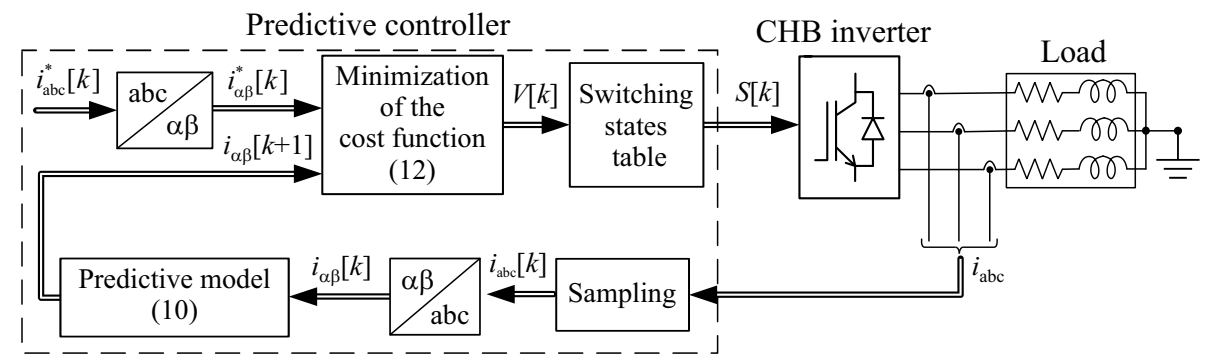

Fig. 3. Block diagram of conventional MPC algorithm for CHB multilevel inverter

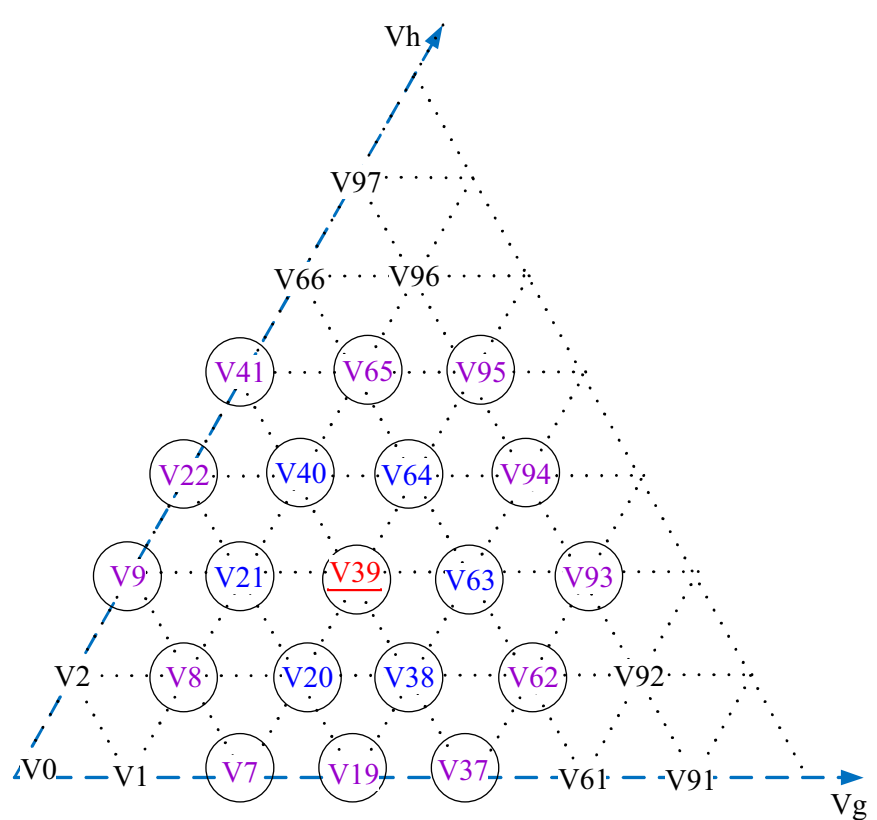

Fig. 4. Illustration for 19 adjacent voltage vectors for one vector (V39)

voltage vector. Hence, the number of nonredundant voltage vectors, which can be determined by (5), is less than the total combinations of switching states [14]

$$
K_{v}=12 n^{2}+6 n+1
$$

In this paper, a three-phase 11-level CHB inverter is used with 1331 possible switching states in static $\alpha \beta$ coordinate. These possible switching states are performed by 331 voltage vectors [23].

\section{Conventional model predictive control}

\subsection{Theoretical basis}

According to Fig. 1 (a), a three-phase CHB multilevel inverter with an RL load has the differential equation of the current in one phase $(a)$ as

$$
v=R i+L \frac{\mathrm{d} i}{\mathrm{~d} t}
$$

where $v=v_{\mathrm{AZ}}, v_{\mathrm{BZ}}, v_{\mathrm{CZ}}$ and $i=\left(i_{\mathrm{a}}, i_{\mathrm{b}}, i_{\mathrm{c}}\right)$.

Using the transformation from $a b c$ frame to static $\alpha \beta$ coordinate [22], (6) can be rewritten as

$$
L \frac{\mathrm{d} i_{\alpha, \beta}}{\mathrm{d} t}=v_{\alpha, \beta}-R i_{\alpha, \beta} \rightarrow \frac{\mathrm{d} i_{\alpha, \beta}}{\mathrm{d} t}=\frac{1}{L}\left\{v_{\alpha, \beta}-R i_{\alpha, \beta}\right) .
$$

Approximating the derivative component in (7) by

$$
\frac{\mathrm{d} i_{\alpha, \beta}}{\mathrm{d} t} \approx \frac{i_{\alpha, \beta}[k+1]-i_{\alpha, \beta}[k]}{T_{s}}
$$

and applying it into (7), then

$$
\frac{i_{\alpha, \beta}[k+1]-i_{\alpha, \beta}[k]}{T_{s}}=\frac{1}{L}\left(v_{\alpha, \beta}[k]-R i_{\alpha, \beta}[k]\right) .
$$

Thus, the future current vector in the next sampling cycle is obtained

$$
i_{\alpha, \beta}[k+1]=\frac{T_{s}}{L}\left(v_{\alpha, \beta}[k]-i_{\alpha, \beta}[k]\left(R-\frac{L}{T_{s}}\right)\right) .
$$

\subsection{Model predictive control}

The MPC controller will choose the voltage vector for the time $\mathrm{k}$ by using the cost function

$$
g_{0}=\left(i_{\alpha, \beta}^{*}[k+1]-i_{\alpha, \beta}[k+1]\right)^{2},
$$

where $i_{\alpha, \beta}^{*}[k+1], i_{\alpha, \beta}[k+1]$ is the reference current vector and the predictive current vector on load at time $[k+1]$. For sufficiently small sampling cycles, it can be assumed that $i_{\alpha, \beta}^{*}[k+1] \approx i_{\alpha, \beta}^{*}[k]$. The cost function (11) is rewritten as

$$
g_{0}=\left(i_{\alpha}^{*}[k]-i_{\alpha}[k+1]\right)^{2}+\left(i_{\beta}^{*}[k]-i_{\beta}[k+1]\right)^{2} .
$$

The cost function (12) is performed for each possible voltage vector. One voltage vector minimizing (12) is chosen to apply to the inverter. The number of voltage vectors evaluated to obtain the optimal solution in each sampling cycle is very high. 
Table 1. Switching states Tab.

\begin{tabular}{cccccc}
\hline$S_{x}$ & \multicolumn{5}{c}{$S_{x i}\left(S_{x i, 1} ; S_{x i, 3}\right)$} \\
& $S_{x 1}\left(S_{x 1,1} ; S_{x 1,3}\right)$ & $S_{x 2}\left(S_{x 2,1} ; S_{x 2,3}\right)$ & $S_{x 3}\left(S_{x 3,1} ; S_{x 3,3}\right)$ & $S_{x 4}\left(S_{x 4,1} ; S_{x 4,3}\right)$ & $S_{x 5}\left(S_{x 5,1} ; S_{x 5,3}\right)$ \\
\hline+5 & $1(1 ; 0)$ & $1(1 ; 0)$ & $1(1 ; 0)$ & $1(1 ; 0)$ & $1(1 ; 0)$ \\
+4 & $1(1 ; 0)$ & $1(1 ; 0)$ & $1(1 ; 0)$ & $1(1 ; 0)$ & $0(0 ; 0)$ \\
+3 & $1(1 ; 0)$ & $1(1 ; 0)$ & $1(1 ; 0)$ & $0(0 ; 0)$ & $0(0 ; 0)$ \\
+2 & $1(1 ; 0)$ & $11 ; 0)$ & $0(0 ; 0)$ & $0(0 ; 0)$ & $0(0 ; 0)$ \\
+1 & $1(1 ; 0)$ & $0(0 ; 0)$ & $0(0 ; 0)$ & $0(0 ; 0)$ & $0(0 ; 0)$ \\
0 & $0(0 ; 0)$ & $0(0 ; 0)$ & $0(0 ; 0)$ & $0(0 ; 0)$ & $0(0 ; 0)$ \\
-1 & $0(0 ; 0)$ & $0(0 ; 0)$ & $0(0 ; 0)$ & $0(0 ; 0)$ & $-1(0 ; 1)$ \\
-2 & $0(0 ; 0)$ & $0(0 ; 0)$ & $0(0 ; 0)$ & $-1(0 ; 1)$ & $-1(0 ; 1)$ \\
-3 & $0(0 ; 0)$ & $0(0 ; 0)$ & $-1(0 ; 1)$ & $-1(0 ; 1)$ & $-1(0 ; 1)$ \\
-4 & $0(0 ; 0)$ & $-1(0 ; 1)$ & $-1(0 ; 1)$ & $-1(0 ; 1)$ & $-1(0 ; 1)$ \\
-5 & $-1(0 ; 1)$ & $-1(0 ; 1)$ & $-1(0 ; 1)$ & $-1(0 ; 1)$ & $-1(0 ; 1)$ \\
\hline
\end{tabular}

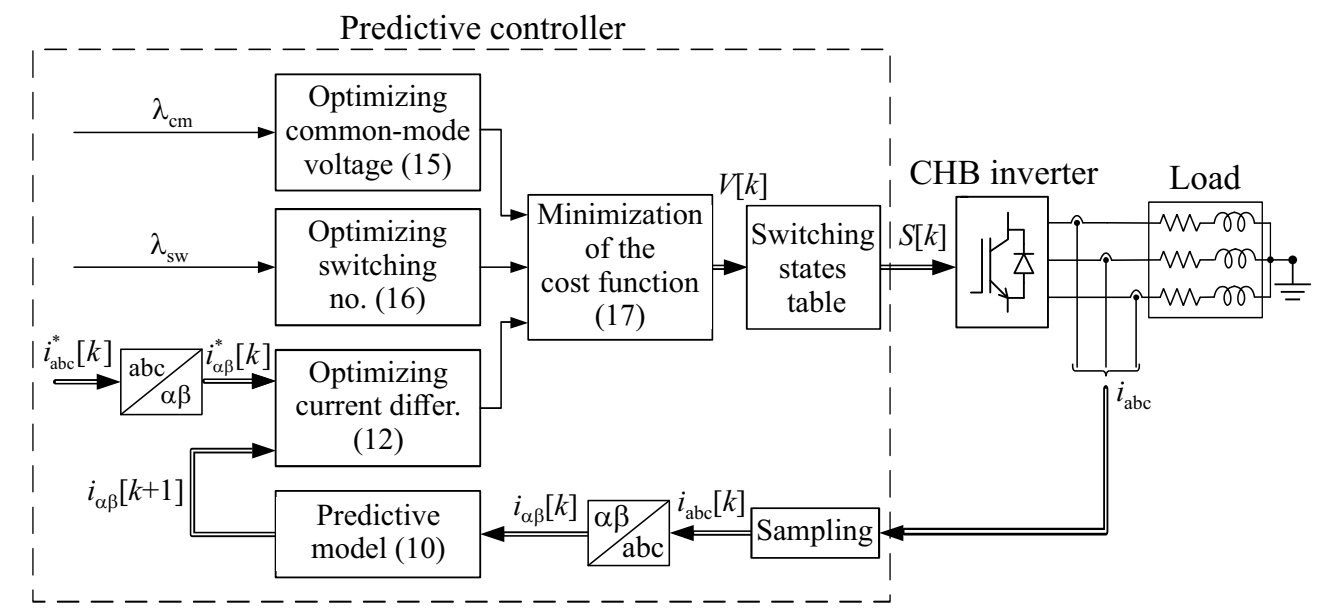

Fig. 5. Block diagram of the proposed model predictive control algorithm

\section{Proposed model predictive control}

\section{1 Reducing the number of calculations for the cost function}

To select the voltage vector having the smallest current difference, it is necessary to calculate the cost function for all voltage vectors that the inverter can generate. For a three-phase 11-level CHB inverter, it generates 1331 switching states (4) and 331 voltage vectors (5). Thus, the cost function (12) will be performed 331 times to choose a voltage vector having the smallest current difference in each sampling cycle. It can be seen that the number of calculations is too large for microcontrollers in one sampling cycle. Especially, when the number of levels increases, the number of calculations will increase rapidly according to (5), that makes increase and the quality of MPC controller decrease. In this study, the author will propose a solution is to use the set of 19 adjacent voltage vectors to solve this problem.

In the steady state, the voltage vector $\mathbf{V}$ is selected sequentially to produce a sinusoidal reference current. Therefore, at two consecutive intervals, the two applied voltage vectors will be approximately equal in amplitude and phase angle. Thus, in each sampling cycle, instead of using 331 voltage vectors to evaluate the cost function, we only need to consider the voltage vector in the previous sampling cycle and 18 adjacent voltage vectors around it. An example for illustration of the set of adjacent voltage vectors is shown in Fig. 4.

The set of adjacent voltage vectors is determined by distances between the voltage vector in the previous sampling cycle and others, which are calculated as

$$
d\left(v_{x}, v_{y}\right)=\sqrt{\left(v_{x, \alpha}-v_{y, \alpha}\right)^{2}+\left(v_{x, \beta}-v_{y, \beta}\right)^{2}},
$$

$v_{y}$ is called as an adjacent voltage vector of $v_{x}$ when $\mathrm{d}\left(v_{x}, v_{y} t\right) \leq \frac{4}{3} V_{\mathrm{dc}}$. The distance calculation will be performed offline and saved to the database of the MPC controller. Each voltage vector has a list of its 19 adjacent voltage vectors.

With this implementation, the cost function is performed only 19 times per sampling cycle. As a result, regardless of the level of $\mathrm{CHB}$ inverter, this way can be applied to reduce the number of calculations of the cost function. 

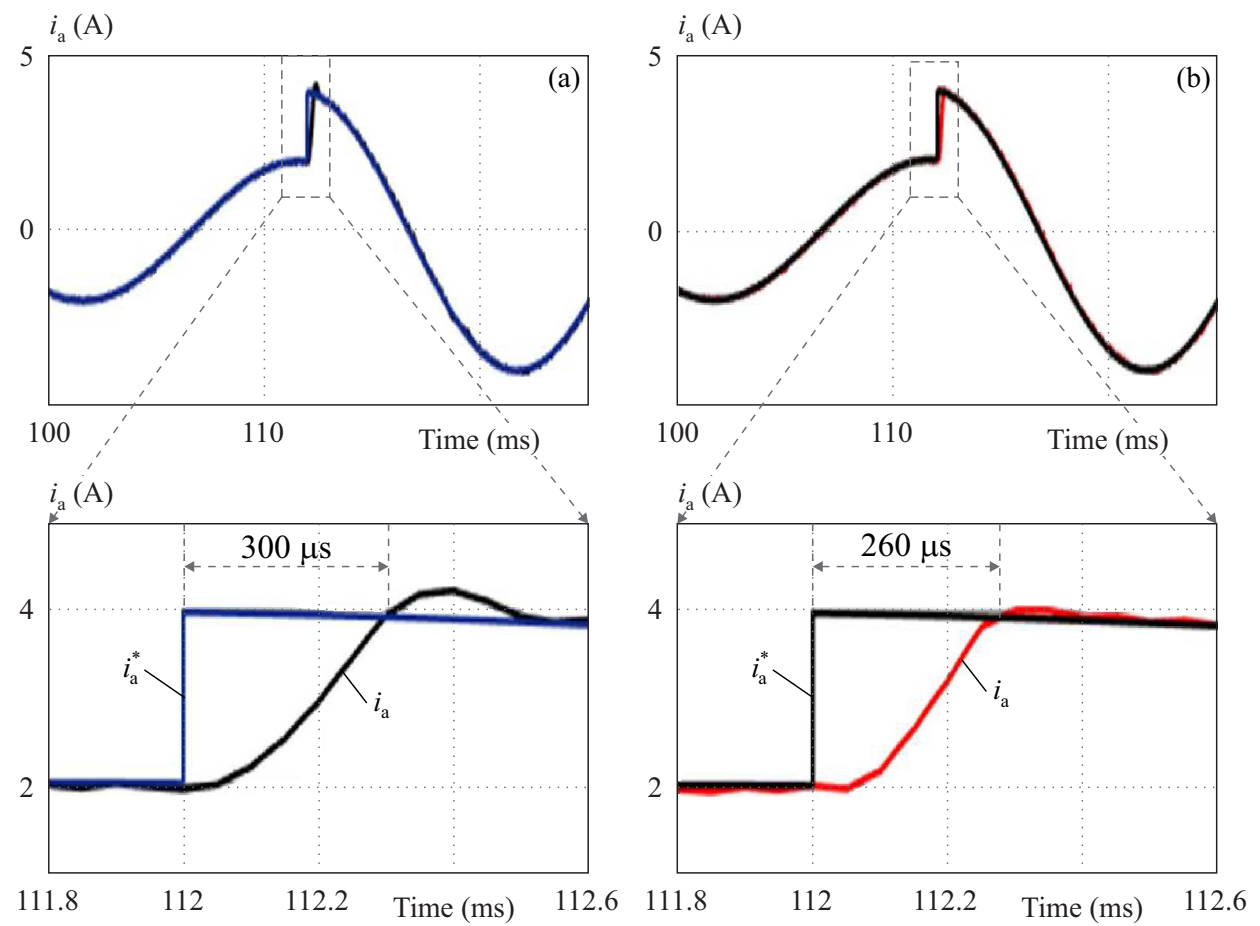

Fig. 6. Measured and reference current in one phase for a step amplitude

The author uses FPGA to program the MPC controller because FPGA has ability of calculating many equations in parallel. The computation time of cost function is minimized. Besides, using 19 adjacent voltage vectors make the responding time to be reduced.

\subsection{Optimizing common-mode voltage}

When the load is connected in star, there is a voltage difference between the load-side neutral and the inverterside neutral, which is called a common-mode voltage (CMV) and denoted by $v_{\mathrm{ZN}}$. Common-mode voltage causes many problems such as shaft voltages and circulating leakage currents through parasitic capacitances between the motor windings, the rotor, and the frame. The amplitude and number of these current spiker is determined by the du/dt and the number of commutations present in the common mode voltage. These current spiker can cause premature motor bearings failures and electromagnetic interference $[24,25]$. Therefore, the optimization of CMV is very important, especially in highvoltage and high-power applications. The common-mode voltage is

$$
v_{\mathrm{ZN}}=\frac{1}{3}\left(v_{\mathrm{AN}}+v_{\mathrm{BN}}+v_{\mathrm{CN}}\right) .
$$

Normally, this voltage will be handled by the inverter's modulation part. Due to not using the modulation part in the MPC algorithm, the optimization of CMV will have to be implemented in the cost function. The part in the cost function optimizing CMV is

$$
g_{1}=\frac{\left|v_{\mathrm{ZN}}[k]\right|}{V_{\mathrm{dc}}},
$$

where $v_{Z N}[k]$ is CMV at the time $k$.

\subsection{Optimizing switching number}

MPC method requires the sampling cycle to be large enough (about $10100 \mu \mathrm{s}$ ). That makes switching frequency increase, resulting in increasing switching losses. Therefore, reducing the switching frequency to improve performance of the inverter is very important. Switching number optimization is also performed in the cost function. The number of switching times after each sampling cycle of the three-phase CHB inverter is

$$
\begin{aligned}
g_{2}=\left|S_{\mathrm{A}}[k]-S_{\mathrm{A}}[k-1]\right|+ & \left|S_{\mathrm{B}}[k]-S_{\mathrm{B}}[k-1]\right| \\
& +\left|S_{\mathrm{C}}[k]-S_{\mathrm{C}}[k-1]\right|,
\end{aligned}
$$

where $S_{\mathrm{A}}, S_{\mathrm{B}}, S_{\mathrm{C}}$ are output voltage levels of three phase $(a, b, c)$ of the inverter. In addition, to perform optimal switching, the suitable voltage levels per phase are specified in Tab. 1

\subsection{Cost function}

In Fig. $5, V[k]=V_{i}=\left[\begin{array}{c}S_{\mathrm{A}} \\ S_{\mathrm{B}} \\ S_{\mathrm{C}}\end{array}\right]$ is the voltage vector at the time k, $S_{x i, j}$ is the $j$ semiconductor switch in the $i$ H-bridge of phase $x(x \in\{A, B, C\}, i=1 \div 5, j=1 \div 4)$. The new cost function for proposed MPC method is

$$
g=g_{0}+\lambda_{\mathrm{cm}} g_{1}+\lambda_{\mathrm{sw}} g_{2},
$$

where $\lambda_{\mathrm{cm}}$ is the weighting coefficient for common-mode optimization and $\lambda_{\mathrm{sw}}$ is weighting coefficient for switching optimization.

The cost function (17) has three objectives: 


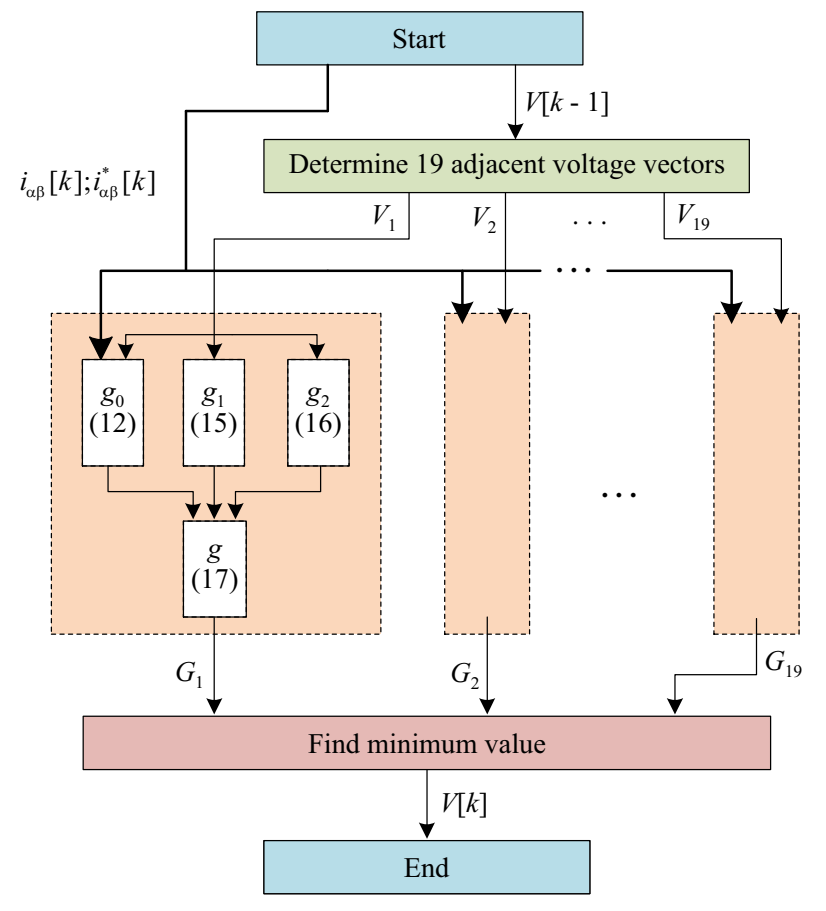

Fig. 7. Block diagram of implementing FCS-MPC on microcontroller

- The first objective $\left(g_{0}\right)$ : Optimizing the difference between the reference and predictive current.

- The second objective $\left(g_{i}\right)$ : Optimizing the commonmode voltage.

- The third objective $\left(g_{2}\right)$ : Optimizing switching number.

The weighting coefficients in the cost function (17) are constant and determined by experiment. However, in different operating processes, the weighting coefficients should be changed to gain the best performance of controller. For example, in the transition stage, the current difference is big, so $g_{0}$ should have a large proportion in the cost function. In steady state, the current difference is small, thus the weighting coefficients of optimizing common-mode voltage and switching number should be bigger to achieve the set target of the controller.

\section{Performance evaluation}

\subsection{Simulation results}

A simulation model of three-phase 11-level CHB inverter in MATLAB-Simulink is used to prove the proposed method. The system parameters are: $20 \mathrm{~V}$ in DC side per power cell, star load has $15 \Omega$ resistor and $3.8 \mathrm{mH}$ conductor per phase, the sampling cycle is $50 \mu \mathrm{s}$. The investigative time is divided into many stages. In each stage, weighting coefficients have specified values, which depend on the target of optimizing the current difference, common-mode voltage or switching number. The investigative situations in detail is shown in Tab. 2, where $I^{*} \mathrm{~A}$ is the amplitude of the reference current.

Table 2. Parameters of weighting coefficients in investigative situations

\begin{tabular}{lccccc}
$(\mathrm{s}) \rightarrow$ & $0-0.05$ & $0.05-0.1$ & $0.1-0.11$ & $0.11-0.2$ & $0.2-0.3$ \\
\hline$\lambda_{\mathrm{cm}}$ & 0 & 0.2 & 0 & 0 & 0.2 \\
$\lambda_{\mathrm{sw}}$ & 0 & 0.04 & 0 & 0 & 0.04 \\
$I^{*}(\mathrm{~A})$ & 2 & 2 & 2 & 4 & 4 \\
\hline
\end{tabular}

At time $0.1-0.2 \mathrm{~s}$, there is a change of reference current amplitude from 2 to 4 , so weighting coefficients are set to 0 . Then, these coefficients are raised to optimize commonmode voltage and switching number.

The behavior of the MPC controller for a step in the amplitude of the reference current is shown in Fig. 7(a). It can be observed that the proposed method has very good reference tracking. The responding time of proposed MPC $(260 \mu \mathrm{s})$ is smaller than the one of 7 adjacent voltage vectors MPC [22] $(300 \mu \mathrm{s})$. The difference is because the proposed method allows bigger changes in the output voltage than method in [22] does, as can be seen in Fig. 8. Besides, the values of $\mathrm{d} v / \mathrm{d} t$ are still within an allowed limit, which greatly improves the motor life.

Simulation results of common-mode voltage is shown in Fig. 9. It shows that the proposed MPC has completely eliminated common-mode voltage, which cannot be done when using method in [22]. Moreover, Fig. 10 shows that the switching number in proposed method is considerably smaller than in [22]. The detail number of switching times in each investigative time $0.02 \mathrm{~s}$ is shown in Tab. 3 .

Table 3. The switching times in phase a after each $0.02 \mathrm{~s}$ with different weighting coefficients

\begin{tabular}{lccc}
\hline $\begin{array}{l}\text { Amplitude } \\
\text { of reference } \\
\text { current }\end{array}$ & $\begin{array}{c}\text { Weighting } \\
\text { coefficient } \\
\text { for optimal } \\
\text { switching } \\
\text { times }\end{array}$ & $\begin{array}{c}\text { The number of } \\
\text { switching times } \\
\text { Method } \\
\text { in }[22]\end{array}$ & $\begin{array}{c}\text { Proposed } \\
\text { method }\end{array}$ \\
\hline $2(\mathrm{~A})$ & 0 & 168 & 168 \\
& 0.04 & 168 & 84 \\
$4(\mathrm{~A})$ & 0 & 92 & 114 \\
& 0.04 & 92 & 28 \\
\hline
\end{tabular}

The reduction of number of switching times make the performance of inverter raise. However, the optimization of common-mode voltage and switching number will raise the \% THD of current, as shown in Tab. 4. As a result, weighting coefficients should be flexible to gain the desired quality of system. 

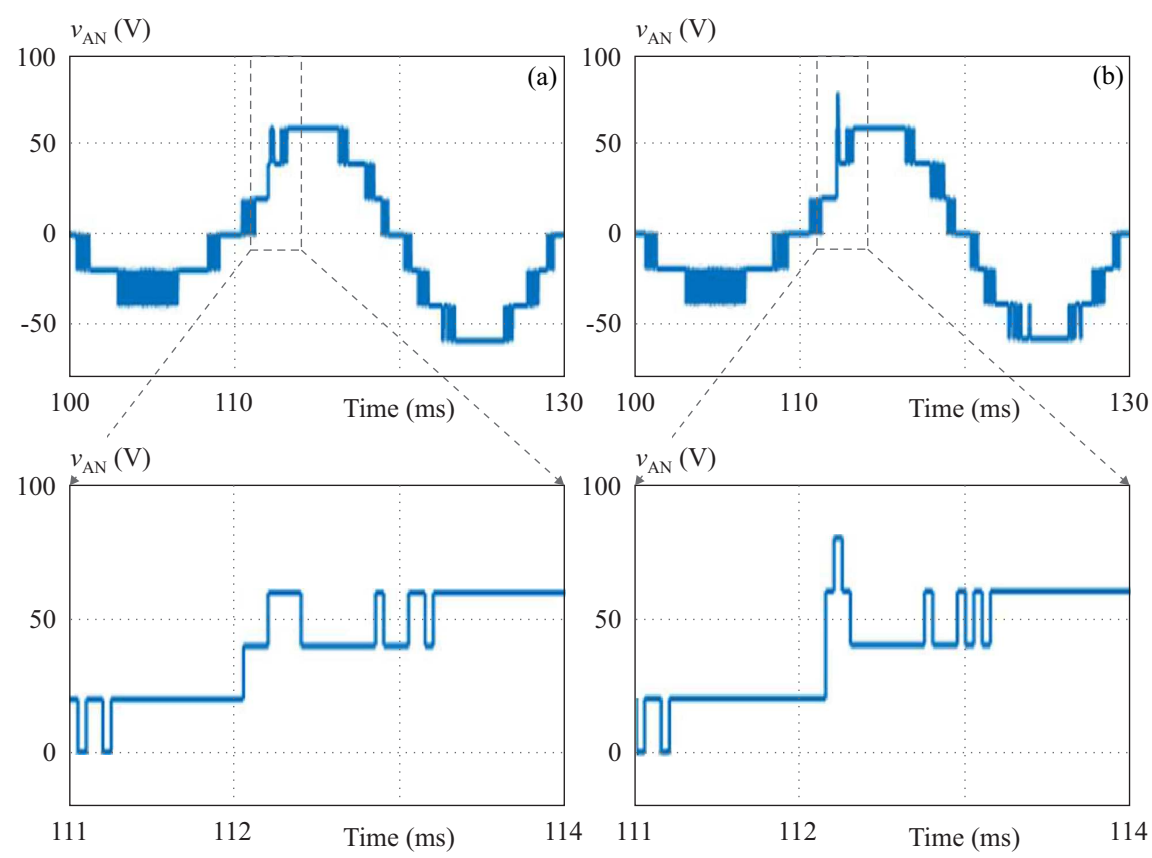

Fig. 8. Inverter voltages for a step change of the reference current is amplitude
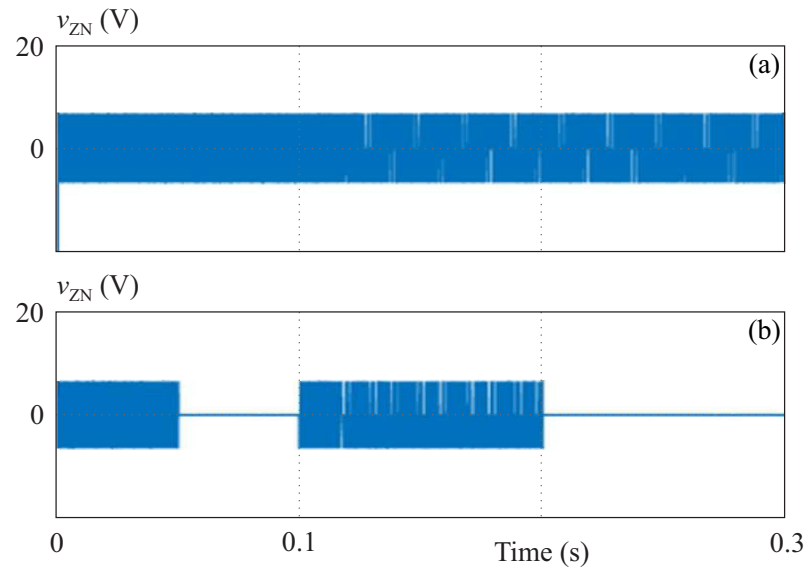

Fig. 9. Common-mode voltage in: (a) - MPC method in [22], (b) Proposed MPC method

Table 4. Analysis for THD of the current in phase $a$

\begin{tabular}{lcccc} 
Time (s) & $0-0.05$ & $0.05-0.1$ & $0.16-0.2$ & $0.2-0.3$ \\
\hline$\lambda_{\mathrm{cm}}$ & 0 & 0.2 & 0 & 0.2 \\
$\lambda_{\mathrm{sw}}$ & 0 & 0.04 & 0 & 0.04 \\
Fundamental & & & & \\
amplitude & 1.99 & 1.95 & 3.99 & 4.04 \\
\% THD & 1.99 & 1.95 & 3.99 & 4.04 \\
\hline
\end{tabular}

\subsection{Experimental results}

The proposed control algorithm was implemented in an FPGA kit Zybo Z7-20 and a three-phase 11-level cas-

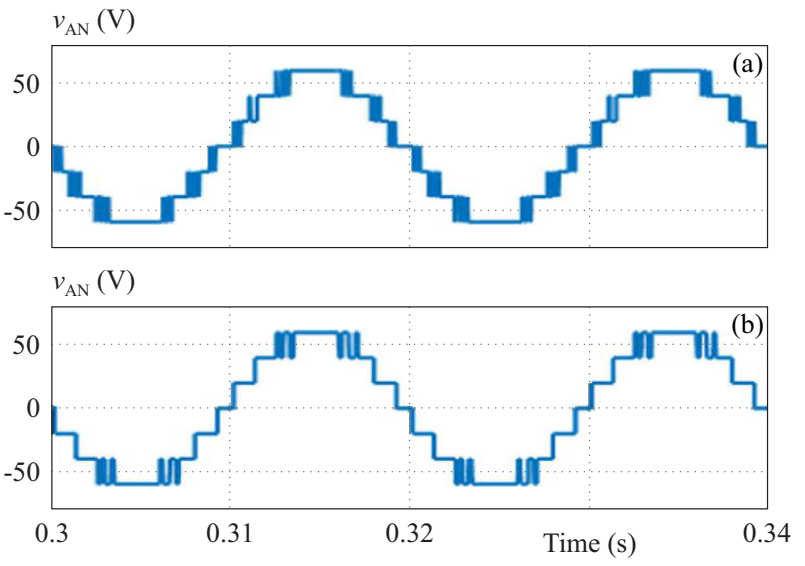

Fig. 10. Output voltage of phase : (a) - MPC method in [22], (b) - Proposed MPC method

caded H-bridge inverter for an RL load. The full experimental model is shown in Fig. 11.

Figure 12 Shows the block diagram of implementing proposed algorithm on kit Zybo Z7. Thanks to the ability of calculating in parallel of FPGA the total computation time of proposed method is equal to the one of method in [22].

To validate the proposed method, the same parameter values are set for both the simulation and experimental model Firstly, the algorithm using 19 adjacent vectors without using weighting coefficients is implemented. The load currents and inverter voltages in three phases for different amplitude values of reference current are shown in Fig. 13 and Fig. 14. 


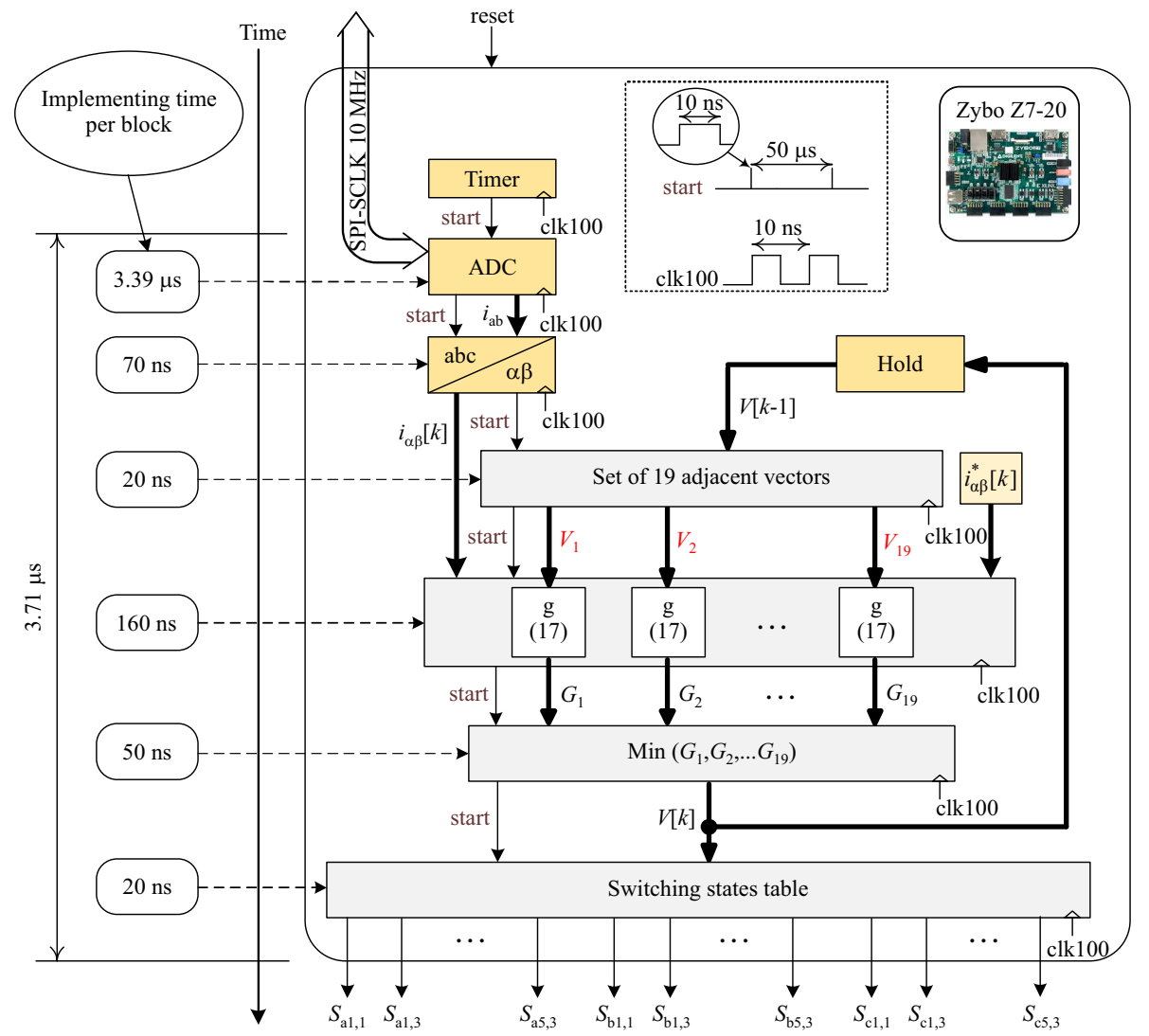

Fig. 11. Block diagram of algorithm implementation on kit Zybo Z7-20

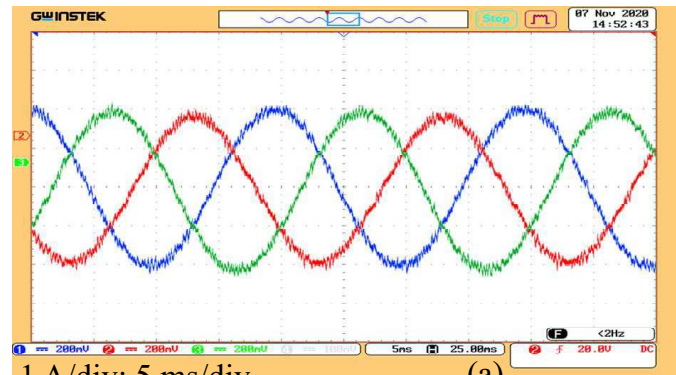

$1 \mathrm{~A} / \operatorname{div} ; 5 \mathrm{~ms} / \mathrm{div}$ (a)

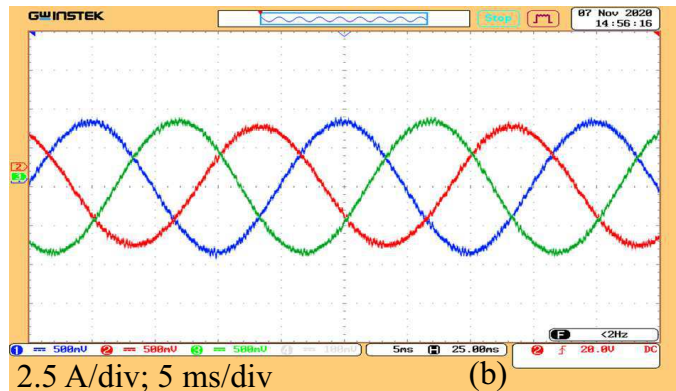

$2.5 \mathrm{~A} / \mathrm{div} ; 5 \mathrm{~ms} / \mathrm{div}$

(b)

Fig. 12. Experimental results Load currents in three phases of inverter, (a) - Amplitude of reference current is 2 A, (b) - Amplitude of reference current is $4 \mathrm{~A}$.

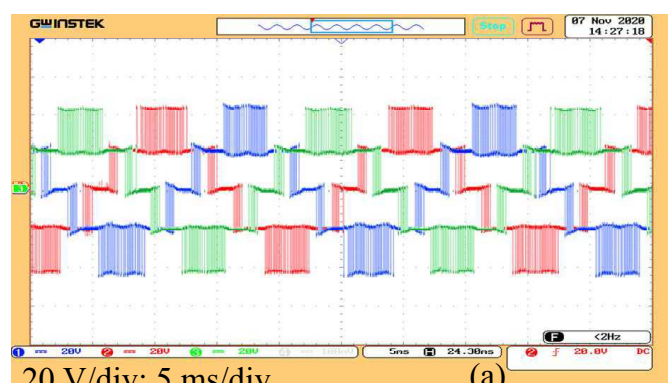

$20 \mathrm{~V} /$ div; $5 \mathrm{~ms} / \mathrm{div}$ (a)

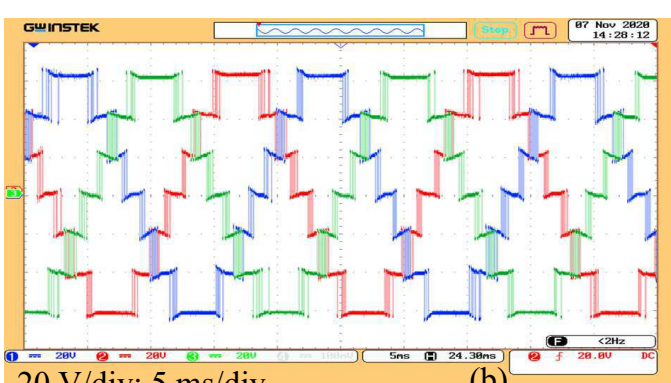

$20 \mathrm{~V} / \mathrm{div} ; 5 \mathrm{~ms} / \mathrm{div}$ (b)

Fig. 13. Experimental results: Three-phase voltages of inverter, (a) - Amplitude of reference current is 2 A, (b) - Amplitude of reference current is $4 \mathrm{~A}$. 

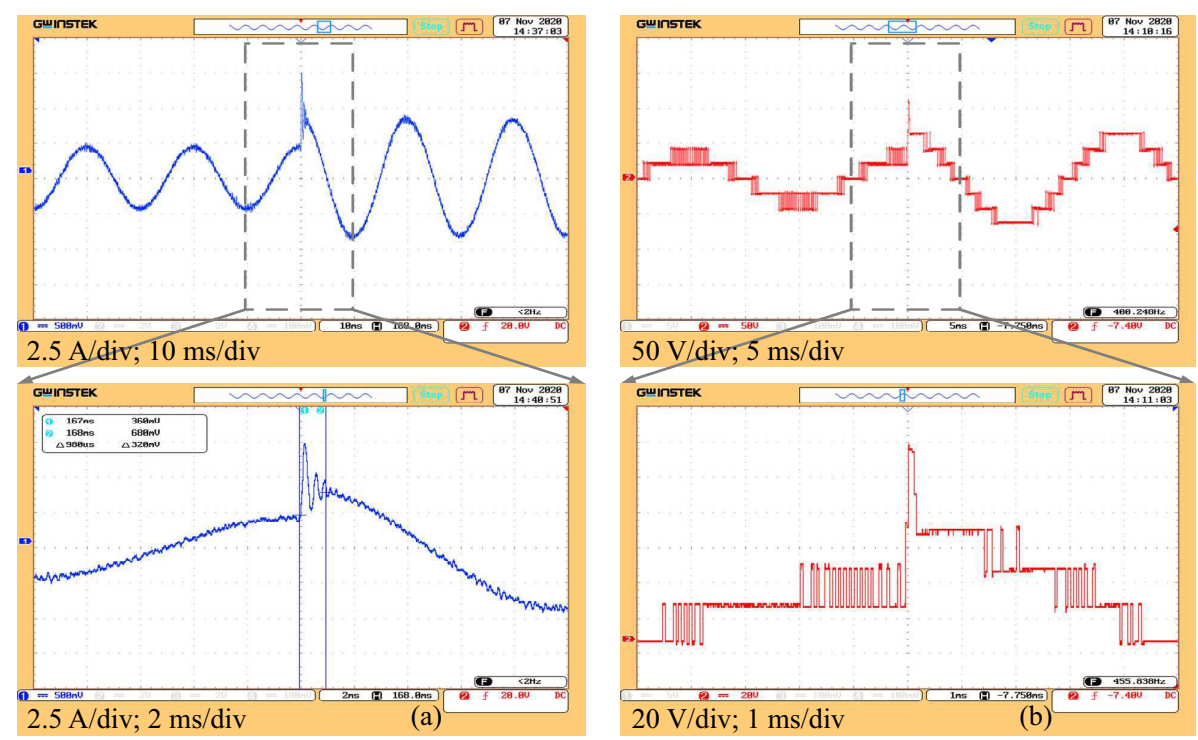

Fig. 14. Experimental results: The behavior of system for a step change in the amplitude of the reference current, (a) - load current in phase, (b) - inverter voltage of phase a
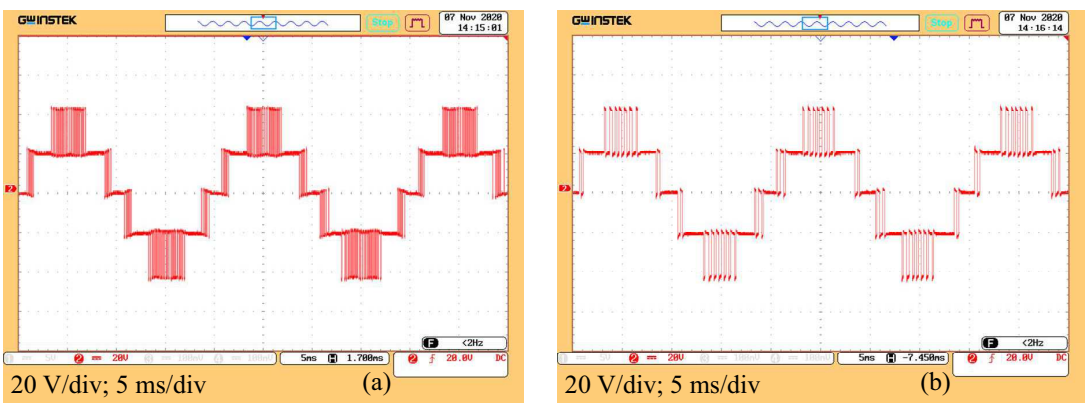

Fig. 15. Experimental results: Voltage of one phase when amplitude of reference current is $2 \mathrm{~A}$, (a) - not using weighting coefficients, (b) - using weighting coefficients
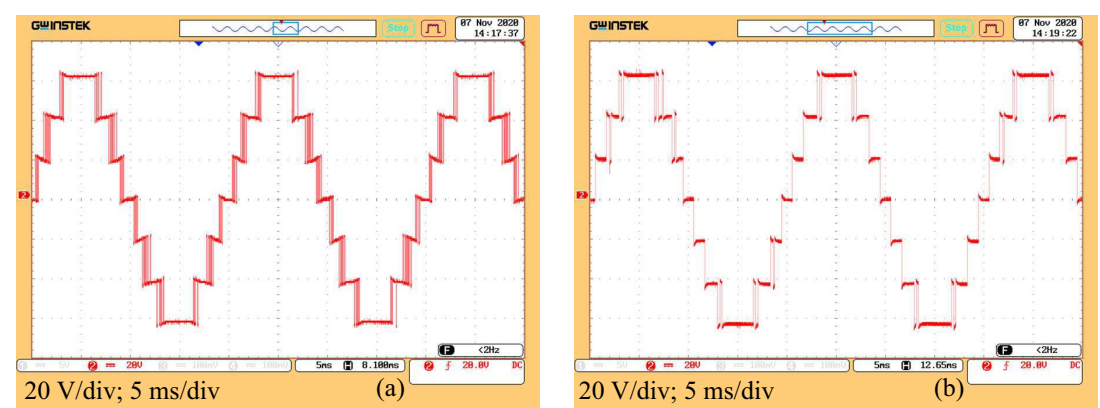

Fig. 16. Experimental results: The behavior of system for a step change in the amplitude of the reference current, (a) - not using weighting coefficients, (b) - using weighting coefficients
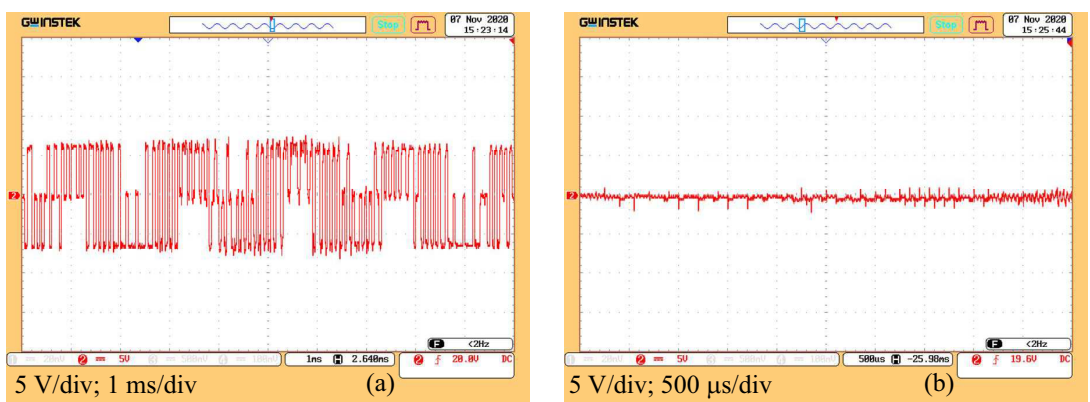

Fig. 17. Experimental results: Voltage of one phase when amplitude of reference current is 2 A, (a) - not using weighting coefficients, (b) - using weighting coefficients 
The load current and inverter voltage in one phase for a step change of the reference current is amplitude is shown in Fig. 15. It can be seen that the experimental results have very similar performance with simulation results. Load current changes follow the reference current very fast (the responding time is about $980 \mu \mathrm{s}$ ).

When system operates in steady state, the weighting coefficients to optimize the common-mode voltage and switching number are added to the cost function. Fig. 16 and Fig. 17 show that the switching number has been reduced considerably. The common-mode voltage has been eliminated completely, as seen in Fig. 18.

\section{Conclusions}

In this paper, a new method of model predictive control has been proposed to eliminate the common-mode voltage and optimize the number of switching times in cascaded H-bridge multilevel inverter. It raises the system's performance by using the set of 19 adjacent voltage vectors without effecting the implementation time. The common-mode voltage can be eliminated completely. Semiconductor switching times is reduced considerably, so the losses of system decrease. This proposed method is quite simple, easy to do in practice and can be applied to $\mathrm{CHB}$ inverter having any voltage levels.

\section{REFERENCES}

[1] J. Gholinezhad and R. Noroozian, "Application of Cascaded H-Bridge Multilevel Inverter DTC-SVM Based Induction Motor Drive", 2012 3rd Power Electronics and Drive Systems Technology (PEDSTC), Tehran, pp. 127-132, 2012.

[2] B. Wu, "Cascaded H-Bridge Multilevel Inverters 7.1", HighPower Converters and AC Drives. pp. 119-142, 2006.

[3] R. José et al "Multilevel Converters: An Enabling Technology for High-Poer Applications", Proceedings of the IEEE, vol. 97, no. 11 pp. 1786-1817, 2009.

[4] J. S. Lai and F. Z. Peng, "Multilevel Converters - A New Breed of Power Converters", IEEE Transactions on Industry Applications, vol. 32, no. 3. pp. 509-517, 1996.

[5] M. Marchesoni, M. Mazzucchelli, and S. Tenconi, "A Nonconventional Power Converter for Plasma Stabilization", IEEE Transactions on Power Electronics, vol. 5, no. 2. pp. 212-219, 1990.

[6] S. Kouro et al "Recent Advances and Industrial Applications of Multilevel Converters", IEEE Transactions on Industrial Electronics, vol. 57, no 8. pp. 2553-2580, 2010.

[7] J. Rodriguez, Jih-Sheng Lai, and Fang Zheng Peng, "Multilevel Inverters: a Survey of Topologies, Controls, and Applications", IEEE Transactions on Industrial Electronics, vol. 49, no. 4, pp. 724-738, Aug, 2002.

[8] B. Hemanth Kumar, M. M. Lokhande,R. R. Karasani, and V. B. Borghate, "Fault Tolerant Operation of CHB Multilevel Inverters Based on the SVM Technique using an Auxiliary Unit", Journal of Power Electronics, vol. 18, no. 1. pp. 56-69, 2018.

[9] F. Z. Peng, W. Qian, and D. Cao, "Recent Advances Multilevel Converter/Inverter Topologies and Applications", The 2010 International Power Electronics Conference - ECCE ASIA, Sapporo, pp. 492-501, 2010.

[10] H. Akagi, S. Inoue, and T. Yoshii, "Control and Performance of a Transformerless Cascade PWM STATCOM with Star Config- uration,", IEEE Trans. Ind. Appl. vol. 43, no. 4, pp. 1041-1049, 2007.

11] C. L. Reddy, P. S. Kumar, M. Sushama, and N. N. V. S. Babu, "A Five Level Cascaded H-Bridge Multilevel STATCOM", 2015 IEEE Asia Pacific Conference on Postgraduate Research Microelectronics and Electronics (PrimeAsia), Hyderabad, pp. 36-41, 2015.

12] F. Khoucha, S. M. Lagoun, K. Marouani, A. Kheloui, and M. E. H. Benbouzid, "Hybrid Cascaded H-Bridge Multilevel-Inverter Induction-Motor-Drive Direct Torque Control for Automotive Applications", IEEE Trans. Ind. Electron. vol. 57, no. 3, pp. 892-899, 2010.

[13] A. Gaikwad and P. A. Arbune, "Study of Cascaded H-Bridge Multilevel Inverter", 2016 International Conference on Automatic Control and Dynamic Optimization Techniques (ICACDOT), Pune, pp. 179-182, 2016.

[14] E. Villanueva, P. Correa,J. Rodriguez, and M. Pacas, "Control of a Single-Phase Cascaded H-Bridge Multilevel Inverter for Grid-Connected Photovoltaic Systems", IEEE Trans. Ind. Electron. vol. 56, no. 11, pp. 4399-4406, 2009.

15] U. Baboo and J. Nakka, "A Grid Connected Cascaded H-Bridge Multilevel Inverter Based Wind Energy System Addressed with the Problem of Power Mismatch Isolated DC Links", 2018 2nd International Conference on Trends Electronics and Informatics (ICOEI), Tirunelveli, pp. 582-585, 2018.

16] Y. Zhang, B. Xia, and H. Yang, "Performance Evaluation of an Improved Model Predictive Control with Field Oriented Control as a Benchmark", IET Electric Power Applications, vol. 11, no. 5. pp. $677687,2017$.

[17] M. M. Bech, J. K. Pedersen, and F. Blaabjerg, "Field-Oriented Control of an Induction Motor using Random Pulsewidth Modulation", IEEE Transactions on Industry Applications, vol. 37, no. 6, pp. 1777-1785, Nov-Dec 2001.

[18] M. P. Kazmierkowski and L. Malesani, "Current Control Techniques for Three-Phase Voltage-Source pwm Converters: A Survey", IEEE Trans. Ind. Electron. vol. 45, no. 5, pp. 691-703, 1998.

[19] S. Kouro, P. Cortés,R. Vargas, U. Ammann, and J. Rodríguez, "Model Predictive Control - A Simple and Powerful Method to Control Power Converters", IEEE Transactions on Industrial Electronics, vol. 56, no. 6. pp. 1826-1838, 2009.

[20] J. H. Lee, "Model Predictive Control: Review of the Three Decades of Development", Int. J. Control. Autom. Syst. vol. 9, no. 3, pp. 415-424, 2011.

[21] J. Rodríguez, J. Pontt, C. Silva, P. Cortés,U. Amman, and S. Rees, "Predictive Current Control of a Voltage Source Inverter", PESC Record - IEEE Annual Power Electronics Specialists Conference, vol. 3. pp. 2192-2196, 2004.

[22] P. Cortes, A. Wilson, S. Kouro, J. Rodriguez, and H. Abu-Rub, "Model Predictive Control of Multilevel Cascaded H-Bridge Inverters", IEEE Transactions on Industrial Electronics, vol. 57, no. 8. pp. 2691-2699, 2010.

[23] C. M. Van, T. N. Xuan,P. V. Hoang, M. T. Trong,S. P. Cong, and L. N. Van, "A Generalized Space Vector Modulation for Cascaded H-Bridge Multi-Level Inverter", Proceedings of 2019 International Conference on System Science and Engineering, ICSSE 2019, pp. 18-24.

[24] I. F. F. Indusity and A. Magazine, "Minimizing Electric Bearing Currents ASD Systems", 1998.

[25] J. Rodríguez, J. Pontt, P. Correa, P. Corés, and C. Silva, "A New Modulation Method to Reduce Common-Mode Voltages Multilevel Inverters", IEEE Trans. Ind. Electron. vol. 51, no. 4, pp. 834-839, 2004.

Received 20 November 2020 
Chung Mai-Van received his MS degree from Hanoi University of Science and Technology, Vietnam in 2016 in Control Engineering and Automation. Since 2017, he has started to study his $\mathrm{PhD}$ degree at Hanoi University of Science and Technology. His research interests include multilevel converter, electrical machine drive.

Sang Duong-Minh has been a student at School of Electrical Engineering, Hanoi University of Science and Technology, Vietnam since 2016. He is a member of Power Electronic Laboratory managed by $\mathrm{PhD}$ Phuong Vu-Hoang. His research interests include cascaded $\mathrm{H}$-bridge multilevel converter and its applications in electrical machine drive and photovoltaic system.

Duc Tran-Huu is a student at Hanoi University of Science and Technology. Since 2018, he has been a member of Power Electronic Laboratory managed by $\mathrm{PhD}$ Phuong Vu-Hoang.
His current research interest are the high-power converters, especially the cascaded H-bridge multilevel inverter.

Bao Binh-Pho received her MS degree from Hanoi University of Science and Technology, Vietnam in 2006 in Control Engineering and Automation. Since 2019, she has started to study his PhD degree at Hanoi University of Science and Technology. Her research interests include multilevel converter, model predictive current control.

Phuong Vu received his BS, MS and PhD degrees from Hanoi University of Science and Technology, Vietnam, in 2006, 2008, and 2014, respectively, all in Control Engineering and Automation. Since 2006 he has been employed at Hanoi University of Science and Technology, where he is a lecturer and researcher at school of electrical engineering. His research interests include modeling and controlling of power electronics converters for applications such as photovoltaic, wind system, electrical machine drive. 